\title{
RUPTURE SINUS OF VALSALVA INTO VENTRICULAR SEPTUM WITH COMPLETE HEART BLOCK
}

\author{
Biswajit Das ${ }^{1}$, Trinath Kumar Mishra ${ }^{2}$
}

\section{HOW TO CITE THIS ARTICLE:}

Biswajit Das, Trinath Kumar Mishra. "Rupture Sinus of Valsalva into Ventricular Septum with Complete Heart Block". Journal of Evolution of Medical and Dental Sciences 2014; Vol. 3, Issue 08, February 24;

Page: 2066-2069, DOI: 10.14260/jemds/2014/2103

\begin{abstract}
An unruptured sinus of valsalva aneurysm can dissect into the interventricular septum (IVS) and cause complete heart block, but a ruptured aneurysm causing complete heart block is rare. We present the case of a young male with ruptured aneurysm into IVS of the right coronary sinus of Valsalva with complete heart block diagnosed by transthoracic echocardiography and electrocardiography.
\end{abstract}

KEYWORDS: Transthoracic echocardiography, sinus of Valsalva aneurysm, complete heart block.

INTRODUCTION: Ruptured sinus of Valsalva (RSOV) is an uncommon condition with protean manifestations. The presentation may range from an asymptomatic murmur to acute cardiogenic shock and death. As clinical examination is not entirely reliable and cardiac catheterization is not always available, echocardiography has become the definitive investigative tool not only to define and diagnose the lesion but also to quantify its severity ${ }^{1}$. In the literature, complete heart block has been reported with unruptured sinus of Valsalva aneurysm. However, it is a very rare complication of RSOV. Thus, we report a case of RSOV into IVS with complete heart block.

CASE REPORT: A 24-year-old man presented with a history of retrosternal chest pain six months back and gradually progressive dyspnea over six months duration. Physical examination of the patient on admission revealed a normal stature (height $168 \mathrm{~cm}$ and weight $53 \mathrm{~kg}$ ) with no marfanoid habitus. Body temperature was $36.8^{\circ} \mathrm{C}$. Blood pressure was $150 / 40 \mathrm{mmHg}$ right arm supine and the pulse was $44 / \mathrm{min}$, regular, high volume, bisferiens pulse. JVP was raised with cannon 'a' wave and the liver was palpable $2 \mathrm{~cm}$ below the right costal margin and was non-pulsatile. There was no ankle edema, but bilateral basal rales in the lungs. A broad cardiac impulse was in left $6^{\text {th }}$ intercostal space. First heart sound was normal with aortic component of second heart sound loud whereas the third and fourth sounds were not audible. A short early diastolic murmur at left 3rd intercostal space with a grade II/VI ejection systolic murmur at left 3rd intercostal space.

Electrocardiogram revealed complete heart block with an atrial rate of $120 / \mathrm{min}$ and ventricular rate of 44/min (Fig. 1). Transthoracic two-dimensional echocardiography (TTE) demonstrated an aorta to interventricular septum fistula through a ruptured right coronary sinus of Valsalva. (Fig. 2). Color-Doppler technique showed shunting of blood from the sinus of Valsalva into the interventriclular septum with presence of moderate aortic regurgitation and enlarged left ventricle (Fig. 3).

There was no evidence of infective endocarditis, rheumatic fever or syphilis on the basis of the patient's history and relevant laboratory analysis. Patient was diagnosed as a case of ruptured sinus of Valsalva into IVS, moderate aortic regurgitation with complete heart block which had 
presented with congestive heart failure and bradycardia. He was put on diuretics. The patient was thereafter referred to the cardio-thoracic surgeon for repair of ruptured sinus of Valsalva aneurysm.

DISCUSSION: RSOV is a rare entity and before echocardiography it was elusive to reliable diagnosis without non-invasive investigations. The unruptured aneurysm is usually silent and generally undiagnosed but may cause symptoms due to right ventricular outflow tract obstruction. ${ }^{1}$ Ninety to $95 \%$ of these congenital aneurysms originate in the right or non-coronary sinus and project into the right ventricle or into the right atrium. Aneurysms arising in the non-coronary sinus almost always rupture into the right atrium. Aneurysms of left coronary sinus rupture into the pericardial space beneath the left coronary artery. ${ }^{2}$ The rupture may also rupture into the left ventricle, the interventricular septum, or the pericardial space ${ }^{3}$.

The aneurysm of the Valsalva sinus seems to be due to the failure of fusion between the aortic media and the heart at the level of the annulus fibrosus of the aortic valve, with subsequent aneurysmal enlargement at this weak point due to the high head of pressure at the root of the aorta ${ }^{4}$. Also, it may be related to diseases of connective tissue such as Marfan's syndrome and Behcet's disease. ${ }^{5}$ Males are more affected than females (4:1 ratio), and the prevalence is higher in the Eastern than in the Western population. Patients are usually diagnosed in the 3rd or 4th decade of life, when rupture occurs and symptoms develop 6 . Complications of sinus of Valsalva aneurysms include aortic regurgitation, decrease in coronary artery blood flow, arrhythmias, endocarditis, and rupture ${ }^{7}$. Cardiac conduction disturbances due to sinus of Valsalva aneurysms occur because of protrusion of aneurysm into the interventricular septum. These conduction abnormalities include sinoatrial conduction disruption, transient or persistent complete atrio-ventricular block, and bundle branch block..$^{8,9}$

The gold standard for diagnosis of this lesion has traditionally been cardiac catheterization and aortography. With the advent of newer generation ultrasound machines, transthoracic echocardiography and trans-esophageal echocardiography ${ }^{10}$ have taken center stage for diagnostic confirmation.

An unruptured aneurysm can compress a proximal coronary or can dissect into ventricular septum and cause complete heart block. In the literature, complete heart block has been reported with unruptured sinus of Valsalva aneurysm; but very few cases of complete heart block with ruptured sinus of Valsalva aneurysm into IVS has been reported.

It is concluded that RSOV into IVS with complete heart block is a rare condition with a varied presentation that sometimes can be fatal, if not diagnosed quickly. Echocardiography is a useful tool to accurately diagnose the ruptured sinus of Valsalva aneurysm. Electrocardiogram must be recorded in every patient to preclude fatal arrhythmias.

\section{REFERENCES:}

1. Malcolm I. Unruptured aneurysm of the sinus of Valsalva. Can J Cardiol 1996; 12: 783-785.

2. Edwards JE, Burchell HB. The pathological anatomy of the deficiencies between the aortic root and the heart including aortic sinus aneurysms. Thorax 1957; 12: 125-39.

3. Kucukoglu S, Ural E, Mutlu H, Ural D, Sonmez B, Uner S. Ruptured aneurysm of the sinus of valsalva into the left ventricle: report and review of the literature. J Am Soc Echocardiogr 1997; 10: 862-865. 
4. Abad C. Congenital aneurysm of the sinus of Valsalva dissecting into the interventricular septum. Cardiovasc Surg 1995; 3: 563-564.

5. Tesler UF, Fiorilli R, Lisanti P. Repair of a ruptured sinus of Valsalva aneurysm. Associated with annulo-aortic ectasia and coarctation of the aorta in a patient with Marfan syndrome. Tex Heart Inst J 1997; 24: 134-138.

6. Miranda D, Peter AA, Osorion J, Ferreira AC. Ruptured aneurysm of the noncoronary sinus of valsalva. Tex Heart Inst J 2005; 32: 586-588.

7. Rigo T, Zeppellini R, Cucchini F. Rupture of an aneurysm of the noncoronary sinus of Valsalva into the right atrium: the "wind sock" echocardiographic appearance. Ital Heart J 2001; 2 (3): 237-8.

8. Ahmad RAS, Sturman S, Watson RDS. Unruptured aneurysm of the sinus of Valsalva with isolated heart block: echocardiographic diagnosis and successful surgical repair. Br Heart J 1989; 61: 375-7.

9. Metras D, Coulibaly AO, Ouattara K. Calcified unruptured aneurysm of sinus of Valsalva with complete heart block and aortic regurgitation. Successful repair in one case. Br Heart J 1982; 48: 507-9.

10. Isomura T, Hisatomi K, Hirano A, Satho T, Kosuga K, Ohishi K. Ruptured aneurysms of the sinus of Valsalva. J Cardiovasc Surg (Torino) 1994; 35:135-138.

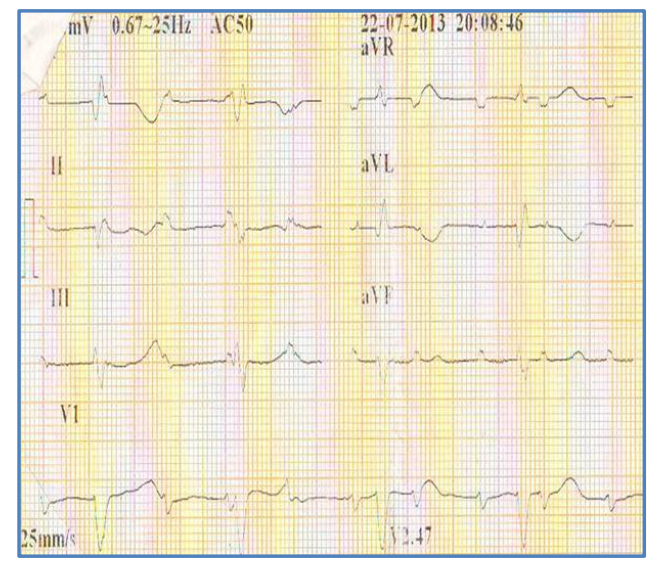

Fig. 1: Electrocardiogram revealed complete heart block with an atrial rate of $120 / \mathrm{min}$ and ventricular rate of $44 / \mathrm{min}$

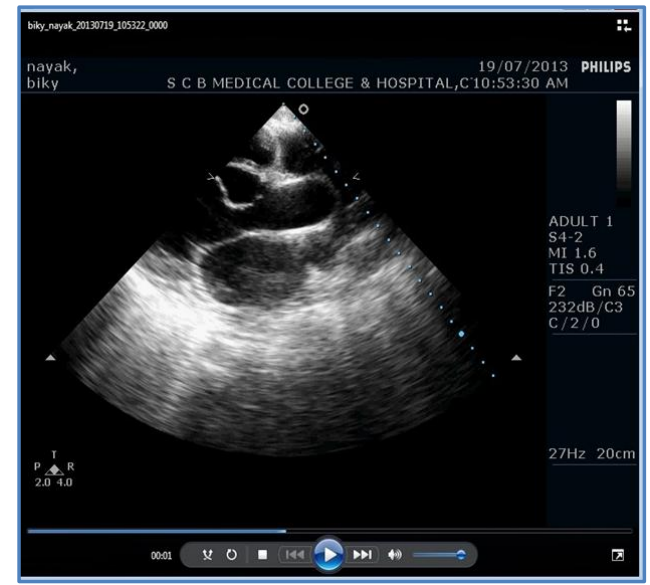

Fig. 2: Transthoracic two-dimensional echocardiography (TTE) demonstrated an aorta to interventricular septum fistula through a ruptured right coronary sinus of Valsalva 


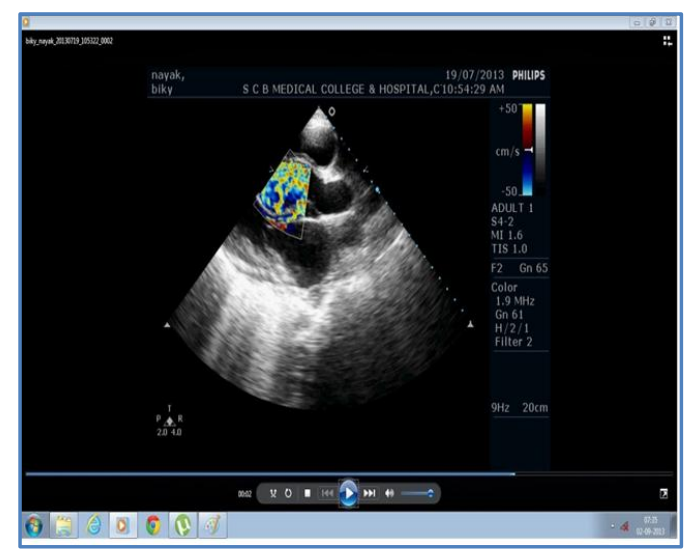

Fig. 3 Colour-Doppler technique showed shunting of blood from the sinus of Valsalva

into the interventriclular septum with prersence of moderate aortic regurgitation and enlarged left ventricle

\section{AUTHORS:}

1. Biswajit Das

2. Trinath Kumar Mishra

\section{PARTICULARS OF CONTRIBUTORS:}

1. Assistant Professor, Department of Cardiology, SCB Medical College, Cuttack, Odisha.

2. Professor and HOD, Department of Cardiology, SCB Medical College, Cuttack, Odisha.

\section{NAME ADDRESS EMAIL ID OF THE CORRESPONDING AUTHOR:}

Dr. Trinath Kumar Mishra, Professor and HOD,

Department of Cardiology, SCB Medical College,

Cuttack - 753007, Odisha.

E-mail:drtkmishra@yahoo.com

Date of Submission: 01/02/2014. Date of Peer Review: 03/02/2014. Date of Acceptance: 08/02/2014.

Date of Publishing: 24/02/2014. 